\title{
6 Monopole Elements Array Intelligent Antennas for IoT Based Environmental Surveillance Network
}

\author{
Elyas Palantei ${ }^{\mathrm{a}, *}$, Arif Hidayat ${ }^{\mathrm{b}}$, Wardi ${ }^{\mathrm{c}}$, Intan Sari Areni ${ }^{\mathrm{d}}$, Sunarno ${ }^{\mathrm{e}}$, Eko Setijadi ${ }^{\mathrm{f}}$, Dewiani Jamaluddin ${ }^{\mathrm{g}}$, Merna \\ Baharuddin $^{\mathrm{h}}$, Ahmad Khatami ${ }^{\mathrm{i}}$, Muhammad Sabirin Hadis $^{\mathrm{j}}$, Akbar Hendra ${ }^{\mathrm{k}}$, Nurfitri Kaharuddin', Priska Wina ${ }^{\mathrm{m}}$, \\ Mainsuri $^{\text {n }}$, Vickyarnoldo Wantura ${ }^{\mathrm{a}}$ and Mulyadi ${ }^{\mathrm{p}}$ \\ aDepartment of Electrical Engineering, Faculty of Engineering, Hasanuddin University. Email: elyas_palantei@unhas.ac.id \\ bLAPAN Pare-Pare, South Sulawesi. E-mail: arif.hidayat81@ gmail.com \\ 'Department of Electrical Engineering Faculty of Engineering, Hasanuddin University. Email: wardi@ unhas.ac.id \\ dDepartment of Electrical Engineering Faculty of Engineering, Hasanuddin University. Email: intan_sariareni@unhas.ac.id \\ eDepartment of Nuclear and Physics Engineering, Universitas Gadjah Mada (UGM), Yogyakarta. Email: sunarno@ugm.ac.id \\ fDepartment of Electrical Engineering, Institut Teknologi Sepuluh Nopember(ITS), Surabaya. Email: e_setijadi@ee.its.ac.id \\ ${ }^{g}$ Department of Electrical Engineering Faculty of Engineering, Hasanuddin University. \\ ${ }^{\text {h} D e p a r t m e n t ~ o f ~ E l e c t r i c a l ~ E n g i n e e r i n g ~ F a c u l t y ~ o f ~ E n g i n e e r i n g, ~ H a s a n u d d i n ~ U n i v e r s i t y . ~ E m a i l: ~ m e r n a @ ~ u n h a s . a c . i d ~}$ \\ ${ }^{i}$ Center of Excellence for Applied Intelligent Technology, Faculty of Engineering, Hasanuddin University \\ jPT. Balla Cerdas Teknologi and STMIK AKBA, Makassar. Email: muhammadsabirinhadis@ gmail.com \\ kPT. Balla Cerdas Teknologi and STMIK AKBA, Makassar. Email: akbarhendra842@gmail.com \\ ${ }^{1}$ Center of Excellence for Applied Intelligent Technology (CEAIT), Faculty of Engineering, Hasanuddin University. \\ E-mail : nurfitri3003@gmail.com \\ ${ }^{m}$ Department of Electrical Engineering Faculty of Engineering, Hasanuddin University. Email: winapriska@gmail.com \\ ${ }^{n}$ Department of Electrical Engineering Faculty of Engineering, Hasanuddin University. Email: mainsuri.postel@ gmail.com \\ ${ }^{\circ}$ Center of Excellence for Applied Intelligent Technology Faculty of Engineering, Hasanuddin University. Email: vickyarnoldo9@ gmail.com \\ pDepartment of Electrical Engineering Faculty of Engineering, Hasanuddin University. E-mail: muliadi7404@unm.ac.id
}

\begin{abstract}
Three types of 6 monopoles array intelligent antennas was numerically and practically examined. The main purposes of the investigation is to guarantee that those designed antennas are feasible to implement and to install in a particular IoT based environmental surveillance network configuration. The basic differences of the three intelligent antennas lied on the frequency operations (i.e. $433 \mathrm{MHz}, 875-915 \mathrm{MHz}$ and $2.5 \mathrm{GHz}$ ) and the actual environment operations (whether for indoor or outdoor). The extreme differences of such frequency operations, of course, affecting the differences on the whole antenna physical dimension. The higher the frequency operation determined then the smaller the physical size of the designed antennas produced. However, the deep intelligent antenna evaluations presented in the paper is the one that operated on frequency band of 875 -915 MHz. The intelligent electronic part of six monopole wire elements arrayed on a circular ground plate was composed of LoRa chip module, Android Uno microcontroller, and the switching network part. The three parts determined whole antenna operation throughout the IoT network. The results of whole antenna examinations are thoroughly discussed in the paper.
\end{abstract}

Keywords: Environmental surveillance; monopole array; intelligent antennas; IoT network

\section{Introduction}

In fact, the classical problems in wireless-based IoT networks such as the effects of multipath propagation fading between the transmitter and receiver units, the noise effects, the limitations of the narrow and expensive bandwidth-spectrum resources and the limitations of RF power could appear as the most serious and critical issues required to overcome. The quality of the IoT network that is built by adopting data / information connectivity techniques such as those that are widely applied in traditional wireless communication networks is largely determined by these important and critical factors [1-20].

\footnotetext{
*Corresponding author. Tel.: +62-812-829-15003

Komplek Perumahan Dosen UNHAS Tamalanrea Blok P1, No.4 Makassar 90245, South Sulawesi Indonesia
}

In general, there are several methods that are very broadly applied to overcome various technical problems in wireless communication networks and which will be widely studied and updated in building and maintaining the quality of IoT networks that are proposed in ongoing research and development (R\&D) activities. 3 types of techniques such as robust adaptive computing algorithms, sophisticated signal processing and adaptive space filtering by optimizing various smart antenna technology innovations (i.e. switched parasitic element configuration category and phased array) will be widely utilized to obtain the more optimum IoT network configuration [516], [18], and [20].

A relatively powerful and simple computing algorithm to mitigate the multipath propagation effects that traditionally encounter throughout the wireless IoT 
Table 1. The physical parameters of the six monopoles array intelligent antennas operated at $875-915 \mathrm{MHz}$

\begin{tabular}{ccc}
\hline Antenna Elements Dimension & Prototype-I & Prototype-II \\
\hline Length of monopole size $(\mathrm{mm})$ & 77.81 & 77.81 \\
$\quad \begin{array}{c}\text { Ground plane diameter }(\mathrm{mm}) \\
\text { Monopole distance from center of } \\
\quad \text { the ground plane (mm) }\end{array}$ & 2830 & 330 \\
$\begin{array}{c}\text { Conducting layer thickness of } \\
\text { ground plane (mm) }\end{array}$ & 0.8 & 80 \\
Monopole wire outer radius (mm) & 3 & 0.8 \\
\hline
\end{tabular}

surveillance networks was extensively studied in the current scientific paper submission. In practical construction the monopole elements array of a single RF feed positioned on top of circular ground plane as suggested in [1-16], [16], [18] and [20] were slightly altered by removing the center feeder and applied computing algorithm to allow all the remaining monopole wires array to become the active elements for a certain operation time interval. The developed intelligent computing algorithm was programmed into an Arduino Uno microcontroller device to steer each monopole wires via the insertion of lumped switching network located exactly underneath of each feeder. The experimental testing of the applied RF-computing method to mitigate the multipath propagation "fading" phenomena in the wireless IoT sensor network is thoroughly analyzed and presented on the following paragraphs.

\section{Numerical Computing and Characterization}

The most common technique adopted to construct various types of the targeted antenna system for any intended applications such as modern communication network, satellite relay system, wireless sensor network and several IoT based wireless applications, is preliminary running the early designed antenna through a numerical computing. Usually, a programmed antenna design has to run, to assess, to characterize and to modify for several number of computing stages so-called the numerical computing optimization processes.

There were three kinds of 6 monopoles array intelligent antennas was practically feasible to implement and to install in order to support whole IoT based environmental surveillance network configured at the new smart campus of the Faculty of Engineering, Universitas Hasanuddin located at Bontomarannu, Gowa regency, South Sulawesi, Indonesia. The basic differences of the three intelligent antennas lied on the frequency operations (i.e. $433 \mathrm{MHz}, 875-915 \mathrm{MHz}$ and $2.5 \mathrm{GHz}$ ) and the actual environment operations (whether for indoor or outdoor). However, the constructed antenna systems and their corresponding discussion for $433 \mathrm{MHZ}$ and $2.5 \mathrm{GHz}$ IoT network applications are not included in the current paper content.

\subsection{The intelligent antennas optimization}

In the current research and development, monopoles array intelligent antennas operated at $875-915 \mathrm{MHz}$ frequency band was designed in such manner to consider the physical parameters tabulated in Table 1. It is clearly shown that the optimized computing process may have several difference output of the targeted antenna numerical design by altering a single monopole planar array, i.e. the distance of the monopole position from the center point of circular ground plane varied from $280.13 \mathrm{~mm}$ to $80 \mathrm{~mm}$. In this case, two types of intelligent monopoles array antennas have been generated through the sequential running of the programmed computing machine. These are called prototype antenna-I and prototype antenna-II, respectively. The two antenna set-up are to resemble and to characterize the impacts of the distance between monopole elements on the planar array configuration to whole antenna system operation performance.

\subsection{Electrical properties comparisons}

The numerical models of the 6 monopole wires planar array configured on top of the circular ground plane sized $330 \mathrm{~mm}$ as visualized in Fig. 1 were schematically drawn and run using a licensed-3D CST software package. Various difference of the computing results were generated and very interesting to analyze further for the purpose of prototype-I and prototype-II electrical properties comparisons.

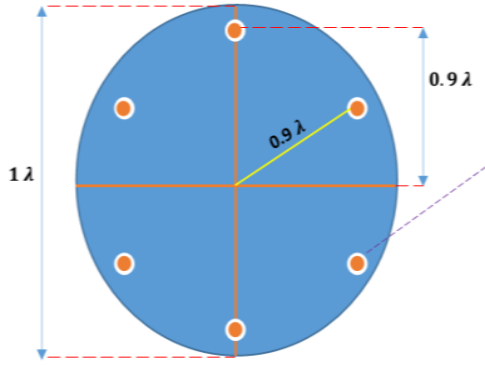

(a)

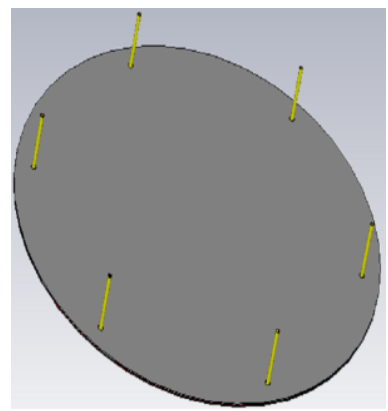

(c)

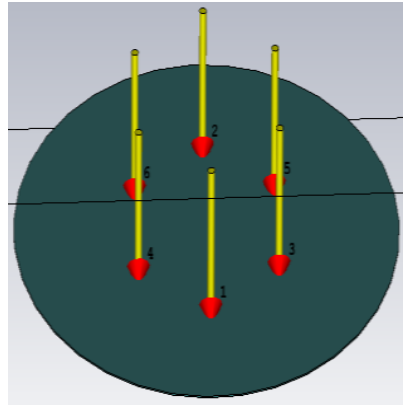

(d)
Figure 1. Two types of 6 monopole wires array configured on top of the circular ground plane sized $330 \mathrm{~mm}$ (a) Top view of prototype antenna-

I; (b) Side view of prototype antenna-I; (c) 3D-planar model of prototype antenna-I; and (d) 3D-planar model of prototype antenna-II

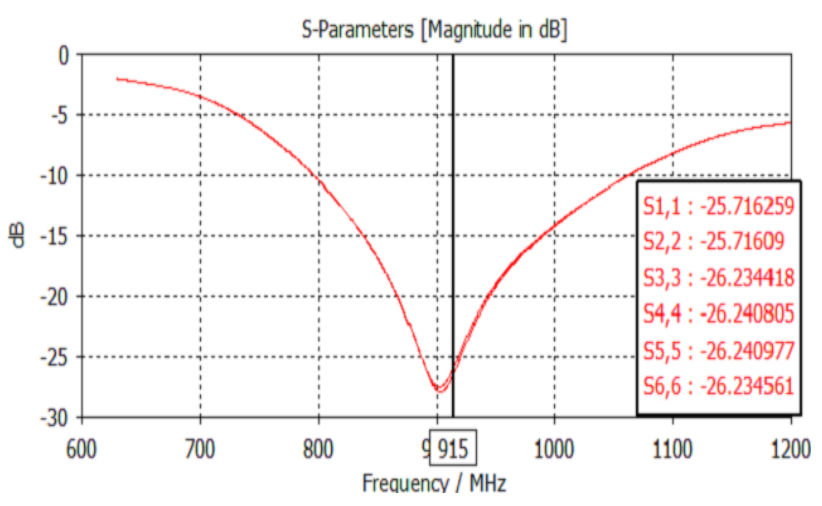

Figure 2. A prototype antenna-I reflection coefficient performance $S_{11}$ (dB) versus operation frequencies $(\mathrm{MHz})$ 
The numerical constructed prototype antenna-I has a pretty excellent reflection coefficient parameter while it operated from $800 \mathrm{MHz}$ up to $1100 \mathrm{MHz}$. It appeared that the identical $S_{11}$ properties were also generated fon all RFfeeding ports, i.e. $\mathrm{S}_{11}$ Port-1 is almost the same to other ports. The broadband frequency could be potentially provided was approximately $300 \mathrm{MHz}$. The recorded VSWR performance of the designed prototype antenna-I appears to have a stable value about 1.1 at all feeding ports while it operates on the frequency $915 \mathrm{MHz}$.

The power radiation pattern of 6 monopoles array intelligent antennas $915 \mathrm{MHz}$ designed to support a typical IoT based environmental surveillance network is depicted in Fig. 4. It is obviously that the $-3 \mathrm{~dB}$ Beamwidth power pattern is in average 98.8 degree. This is quite broad pattern could be provided during the transmission of various data from the sensor node to reach the server terminal. Both pattern in the front direction and in the back direction is almost the same. FTBR is quite small value and it is around few $\mathrm{dBi}$. This also resembles the potential to connect and to monitor more sensor nodes inside the operated network remotely through the base station server terminal.

When the six monopoles position were set-up to more close each other and to approach the center point of the circular ground plane (see Fig. 1. (d)) than the previous prototype antenna-I the unsatisfied electrical properties of the prototype antenna-II were generated. Both the S11 and VSWR profiles tends to have the poor values (see Fig.s 5 and 6). At the operation frequency $915 \mathrm{MHz}$ all ports only produced about $-9 \mathrm{~dB}$. This is equivalent to 2.2 Voltage Standing Wave Ratio (VSWR).

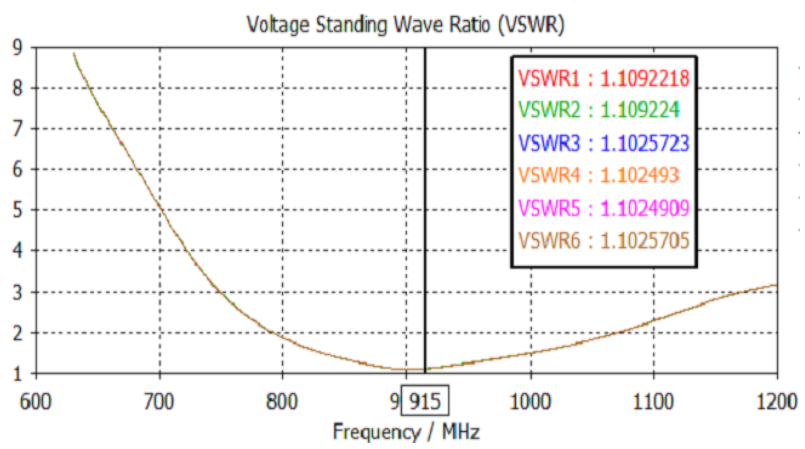

Figure 3. A prototype antenna-I VSWR property versus operation frequencies $(\mathrm{MHz})$

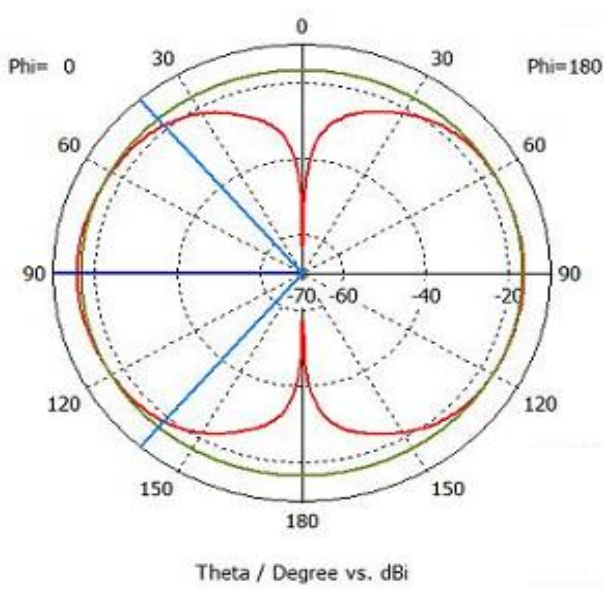

Figure 4 . The prototype antenna-I power radiation pattern of 6 monopoles array intelligent antennas $915 \mathrm{MHz}$

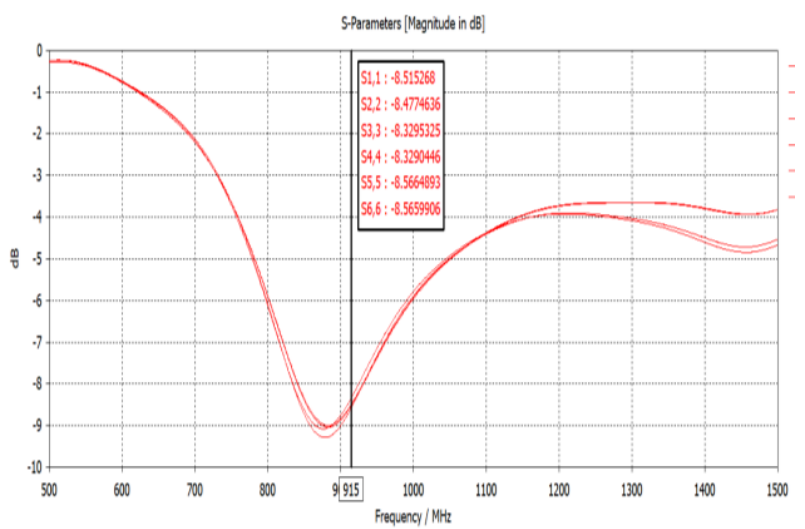

Figure 5. A prototype antenna-II reflection coefficient performance $S_{11}$ (dB) versus operation frequencies $(\mathrm{MHz})$

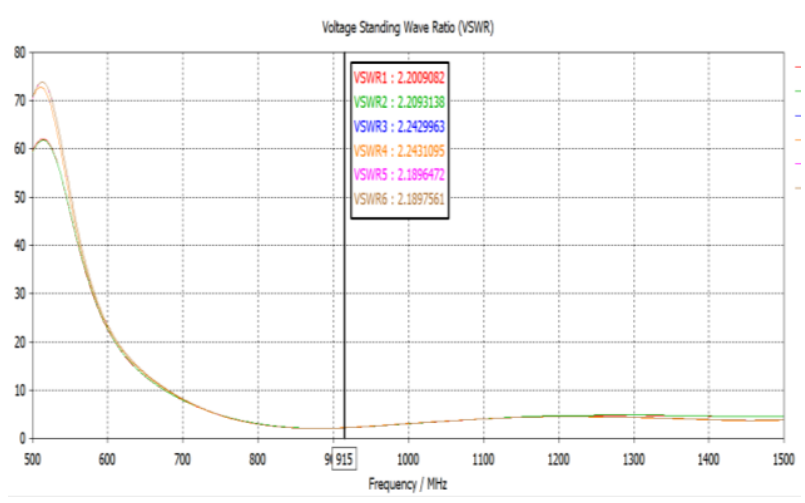

Figure 6. A prototype antenna-II VSWR property versus operation frequencies $(\mathrm{MHz})$

Despite the destroyed S11 and VSWR electrical properties generated as the distance range amongst the monopole wires of prototype antenna-II to set-up smaller than another antenna type, however, the interested power pattern were produced as one monopole wire activated and others 5 elements inactivated (floating status). Two identical power patterns illuminated from two different ports were activated on two different sequential operation times. These are shown in Fig. 7. The probability of other ports to have the similar power pattern but in the different main lobe directions are relatively high depending on the accuracy of each monopole wires placement on the conducting ground plane during the computation.

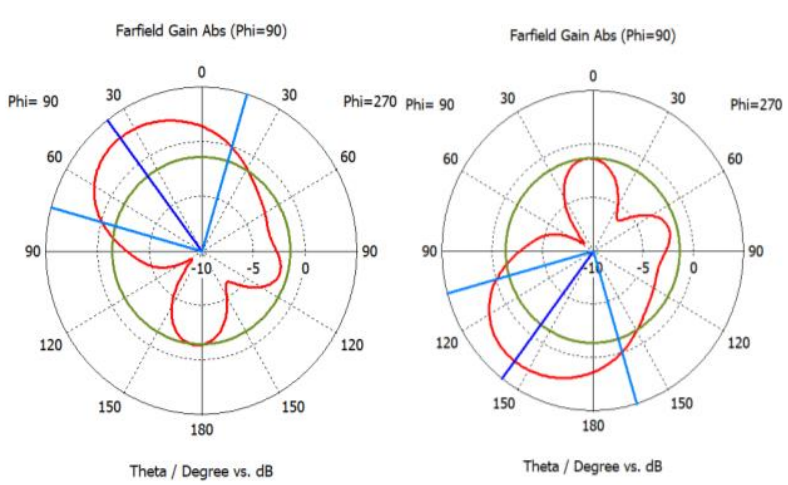

Figure 7. The prototype antenna-II power radiation pattern of 6 monopoles array intelligent antennas $915 \mathrm{MHz}$ 
Both the FTBR and the $-3 \mathrm{~dB}$ Beamwidth power pattern produced by the prototype antenna-II are better than the prototype antenna-I has generated. FTBR produced is almost $5 \mathrm{dBi}$. While, the $-3 \mathrm{~dB}$ Beamwidth power pattern is approximately 91.5 degree.

\section{Manufacturing, Testing and Evaluating}

A fabricated 6 monopole wires planar array intelligent antenna incorporated into a particular wireless IoT based environmental surveillance network is described in Fig. 8. The physical size of the constructed antennas placed on both the transmitting and the receiving parts was set-up according the parameters listed in Table 2. The antennas will maintain the quality of both signals transmission and reception throughout the operated IoT network to combat the multipath fading effects.

In principle the typical wireless IoT based environmental sureveillance configured as visualized in Figure 8 will collect all data from the connected sensors and further processed in the transmitting electronic part. The adaptive transmitter unit consists of an array of the environmental sensors, Arduino Uno microcontroller device, LoRa module chip and the transmitting antenna. Meanwhile, in the intelligent receiving electronic part some processing units (i.e. receving antenna, LoRa chip module and Arduino Uno microcontroller) were connected each other in order to reprocessed the received data and to feed forward to a PC/ laptop server unit.

The main purpose of the measurement configuration set-up for an indoor $915 \mathrm{MHz}$ IoT network environment as described in Fig. 9 is to compare the performance of a conventional single monopole wire antenna that usually attached inside the LoRa module with the performance of the constructed 6 monopole wires planar array intelligent antennas. One of the interesting practical testing result on the performance of an indoor IoT based surveillance system employed 6 monopole wires array intelligent antennas is portrayed in Fig. 10.
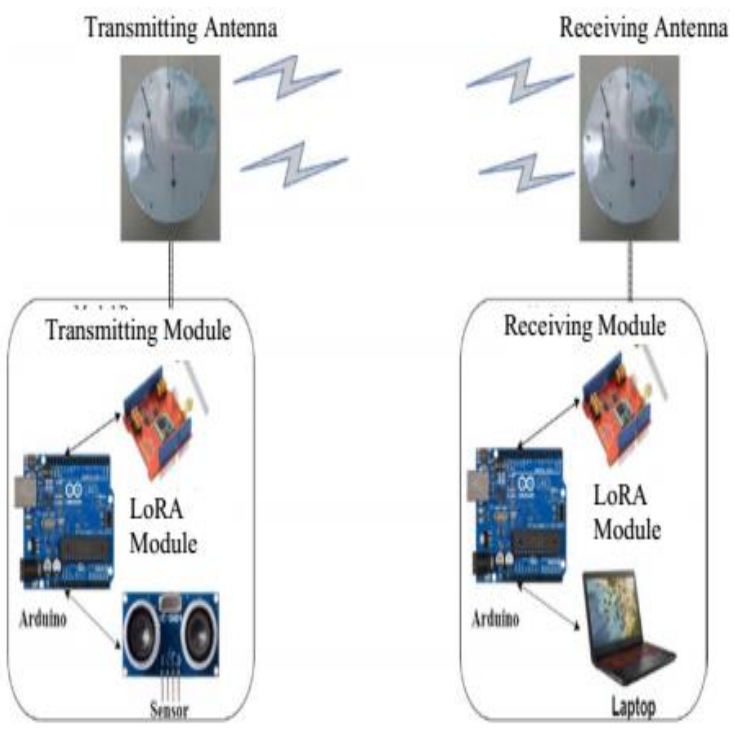

Figure 8 . The 6 monopole wires planar array intelligent antenna incorporated into a particular $915 \mathrm{MHz}$ wireless-IoT based environmental surveillance network
Table 2. The physical parameters of the six monopoles array intelligent antennas operated at $875-915 \mathrm{MHz}$ frequency band

\begin{tabular}{cc}
\hline Antenna Elements & Dimension $(\mathbf{m m})$ \\
\hline $\begin{array}{c}\text { Length of monopole } \\
\text { Ground plane diameter } \\
\text { Monopole distance from center of } \\
\quad \text { the ground plane }\end{array}$ & 80 \\
$\begin{array}{c}\text { Distance separation between each } \\
\text { monopole wire elements }\end{array}$ & 830 \\
$\begin{array}{c}\text { Conducting layer thickness of } \\
\text { ground plane }\end{array}$ & 82.5 \\
Monopole wire outer radius & 0.8 \\
\hline
\end{tabular}
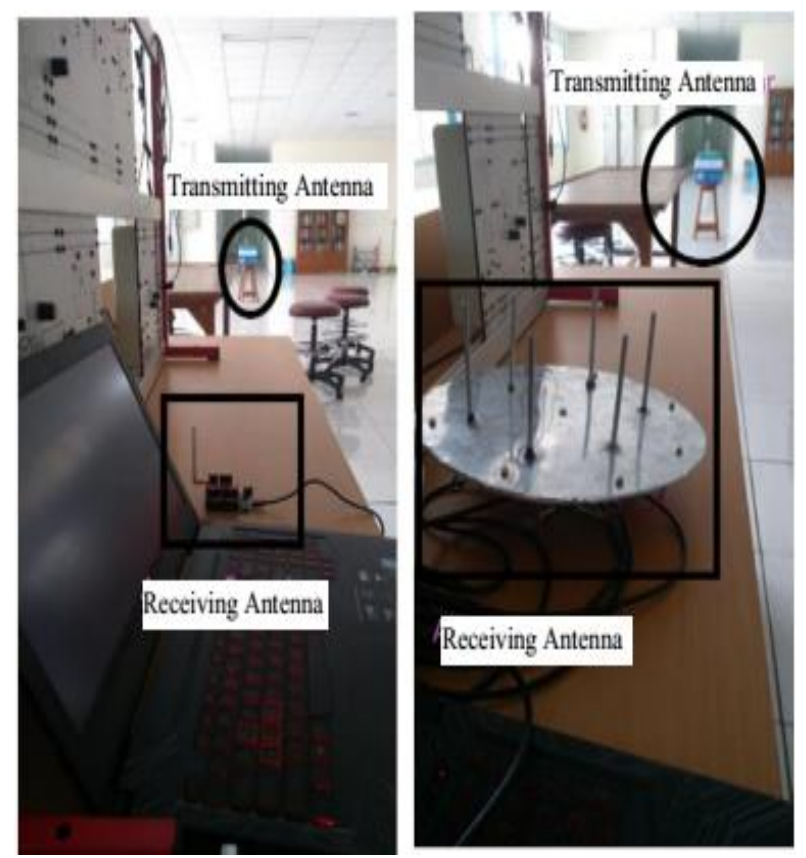

Figure 9. The measurement configuration set-up in the indoor $915 \mathrm{MHz}$ IoT network environment

It is obviously that, as described in Fig. 10., the deployment of the constructed antennas on both the transmitting part and the receiving part might significantly maintaining on the stable power reception of approximately $-60 \mathrm{dBm}$ while the mobile sensor nodes removing. It is contradicted with the installed single monopole antenna opponent which the quality of the signal receptions appeared unstable while the sensor node module was repositioned away from the base server station terminal. The fluctuated signal receptions of approximately $60 \mathrm{~dB}$ power might encountered throughout the IoT network while using this antenna during the operational period.

Another interesting experimental examination obtained during the trial mobile testing in the outdoor environmental operation of IoT based surveillance system was demonstrated in Fig. 11. On this practical testing the sensor node was removed away up to several hundred meters outside the building of LAPAN Pare-Pare remote sensing office. Only the constructed 6 monopole wires planar array intelligent antennas were installed on both two transceiver parts and one sensor node part was positioned inside a carried box. 


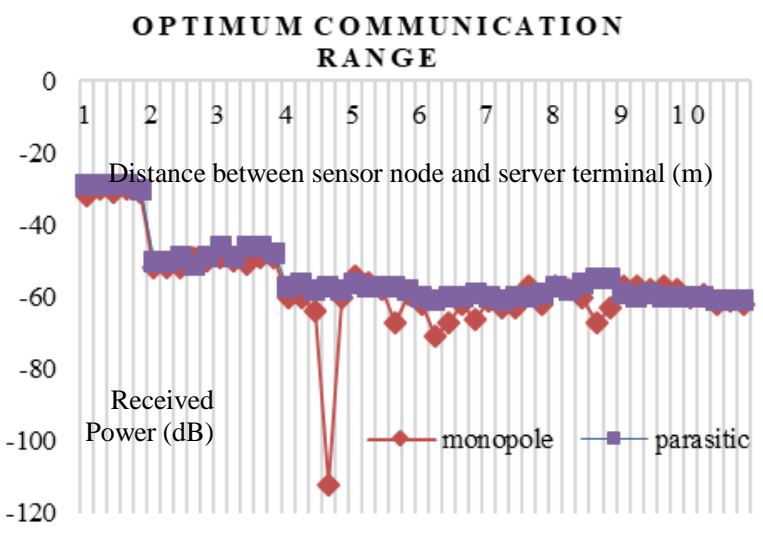

Figure 10. The measurement configuration set-up in the indoor 915 MHz IoT network environment
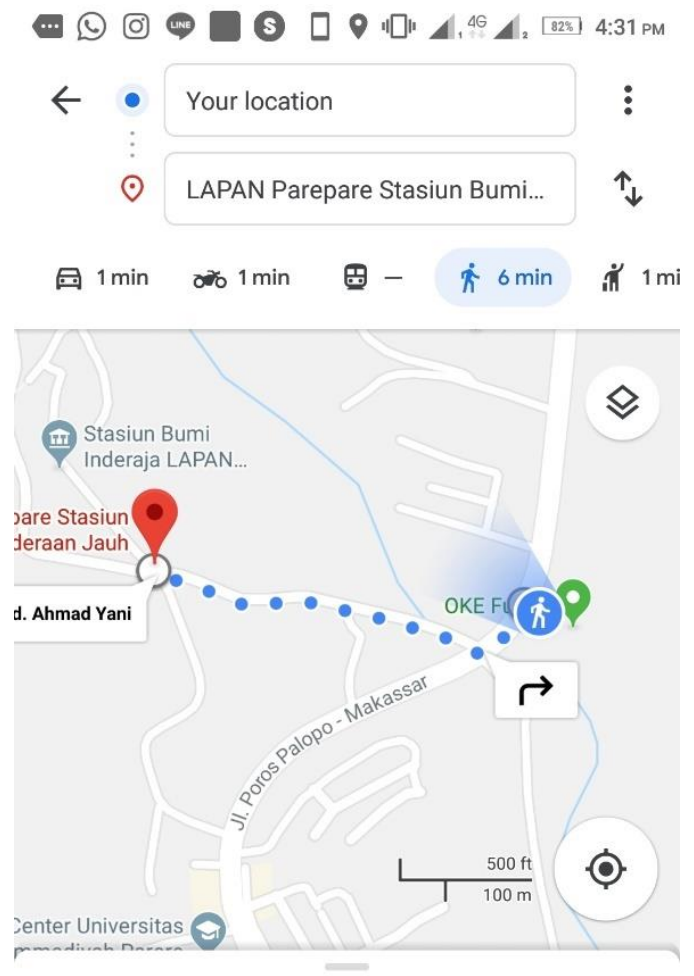

$6 \min (450 \mathrm{~m})$

via Jl. Pare-Pare - Sidrap/JI. Poros Palopo - Makassar

$$
\triangle \text { Start }: \equiv \text { Steps } \& \text { more }
$$

Figure 11. The outdoor measurement set-up of the IoT transceiver in a particular sub urban environment located in Pare-Pare city, South Sulawesi province

The observer is then moving to follow the below figure of the walking track. Based on the experimental activity described in Fig. 11, it is clearly seen that the maximum communication distance between the mobile IoT based sensor node and the operated fix position of central collected server inside LAPAN office building is no more than 450 meters distance. Over that distance range the more failure data and connection problem encountered during the actual measurement and data recording.

\section{Concluding Remarks}

The 6 monopole wires array intelligent antennas was numerically and practically constructed and characterized to be suitable employed in the $875-915 \mathrm{MHz}$ wireless IoT based environmental surveillance. The manufactured switched parasitic antenna was incorporated into IoT network and was tested for both the indoor and outdoor environments. Both for the two operation environments the designed intelligent antennas outperformed the conventional single monopole antenna in terms the stability of signal reception. The smart parasitic antenna has also had the better read/communication range between the sensor node and the server terminal than using the single monopole antenna. The longest communication distance recorded no more than 450 meter. Over this range more failure data receptions encountered along the free space communication link.

\section{Acknowledgements}

Authors would like to thanks to the Ministry of Research and Technology/ BRIN, Republic of Indonesia for providing the sufficient funding to allow the ICT R\&D group at Universitas Hasanuddin together with others collaborator higher education institutions such as UGM and ITS, and other national research and industry partners (PT. Lapan Pare-Pare and PT. Balla Cerdas Teknologi) to implement various ICT R\&D products focusing on the smart antennas development since 2019. Authors would also like to extend our sincere thanks to any people who are indirect or directly contributing for many achievements gained during the $R \& D$ process period.

\section{References}

[1] S.L. Preston, D.V. Thiel, T.A. Smith, S.G.O'Keefe, and J.W. Lu, 1998. "Base Station Tracking in Mobile Communications Using a Switched Parasitic Antenna Array". IEEE Transactions on Antennas and Propagation. Vol. 46. No.6. June 1998. pp. 841-844.

[2] S.L. Preston, D.V. Thiel and J.W. Lu, 1999. "A Multibeam Antenna Using a Switched Parasitic and Switched Active Elements for Space Division Multiple Access Applications". IEICE Transactions on Electronics. Vol. E82-C. No.7. July 1999. pp. 1202-1210.

[3] D. V. Thiel and S. Smith, Switched Parasitic Antennas for Cellular Communications, Artech House, Inc., 2002.

[4] R.W. Schlub, and D.V. Thiel., 2004. "Switched Parasitic Antenna on a Finite Ground Plane with Conductive Sleeve". IEEE Trans. Antennas and Propagation, Vol.52, (5), pp. 1343-1347, May 2004.

[5] E. Palantei and D.V. Thiel, "Electronically Switched Parasitic Smart Antenna for Wireless Communication", Conference Digest of the $9^{\text {th }}$ Australian Symposium on Antennas, Sydney, Australia, pp.24, 16-17 Feb. 2005.

[6] E. Palantei and D.V. Thiel, "An Investigation of an Electronically Switched Beam Smart Antenna: Numerical and Empirical Approaches." Digest of Microelectronic Engineering Research Conference (MERC) 2005, South Bank, Brisbane, Australia, 2-3 November 2005.

[7] E. Palantei and D.V. Thiel, "Controller Algorithms for Single Feed Switched Parasitic Antennas," IEEE AP-S International Symposium, USNC/URSI National Radio Science and AMEREM Meetings, Albuquerque, New Mexico, USA, 9 -14 July 2006: pp.378.

[8] E. Palantei and D.V. Thiel, "Current Variations of Parasitic Monopoles: Its Impact on the Performance of Switched Beam Smart Antenna", Asia-Pacific Symposium on Applied Electromagmetics and Mechanics (APSAEM) 2006, University of Technology Sydney (UTS), Sydney, Australia, 20-21 July 2006.

[9] E. Palantei and D.V. Thiel, "Symmetry Problems in Switched Parasitic Smart Antennas", IEEE Antennas and PropagationSociety(APS)International Symposium, Honolulu, HI, USA, 10-15 June 2007: pp. 3360-3363. 
[10]E. Palantei and D.V. Thiel, "The Impact of Bias Voltage on the Performance of a P.I.N. Diode Loaded Smart Antenna," Journal of the Japan Society of Applied Electromagnetics and Mechanics (JSAEM),Vol.15, No.3, September 2007, pp.274-277.

[11]E. Palantei and D.V. Thiel, "Dual Frequency Plug and Play of Steerable Antenna for ISM band Communication," International Conference on Electrical Engineering and Informatics (ICEEI) 2007, Institut Teknologi Bandung, Bandung, Indonesia, 17-19 June 2007.

[12]E. Palantei, D. V. Thiel, and S.G. O'Keefe, "Reconfigurable Intelligent Antennas using a Switched Constellation of Parasitic Elements," Digest of GSERC 2007 conference, Logan Entertainment Centre, Qld, Australia, 29-30 October 2007.

[13]E. Palantei, D. V. Thiel, and S.G. O'Keefe, "Rectangular Patch with Parasitic Folded Dipoles: A Reconfigurable Antenna," Proceedings of the IEEE International Workshop on Antenna Technology (IEEE iWAT) 2008: Small Antennas and Novel Metamaterials, 4-6 March 2008, Chiba, Japan.

[14]E. Palantei and D. V. Thiel, "Comments on A Novel Planar Switched Parasitic Array Antenna with Steered Conical Pattern," IEEE Transactions on Antennas and Propagation, Vol. 56, No.9, September 2008, pp.3084.

[15]E. Palantei and D.V. Thiel, "Circular Monopole Array Antenna with Intelligent Electronic Circuit at the Bottom Side of Cylindrical Ground Structure" to be submitted to IEEE Transactions on Antennas and Propagation.
[16]E. Palantei, S. Kanata, N.K.Subaer, Adnan, Z.B. Hasanuddin, D Djamaluddin, I.S. Areni, Indrabayu, Wardi, and D.V Thiel, "Prototyping Plug and Play Smart Antenna untuk Aplikasi Generasi Lanjut Sistem Komunikasi Nirkabel," Research Report of Program Dukungan R\&D Produk Telekomunikasi, Research Grant awarded by General Directorate of Post and Telecommunication, Ministry of Communication and Information, Republic of Indonesia, 2007-2009.

[17]D. V. Thiel, "Progress in Wireless Sensor Design and Networking," Proceedings of $1^{\text {st }}$ Macassar International Conference on Electrical Engineering and Informatics (MICEEI), Macassar, South Sulawesi, Indonesia, 13-14 November 2008.

[18]E. Palantei, S. Syarif, A. Hidayat dan STA. Munawar, "Low-Cost Switched Array- Wide Band Antenna for Search and Rescue Disaster," The $3^{\text {rd }}$ IEEE-International Conference on Science and Technology, Yogyakarta, Indonesia, 11-12 July 2017.

[19]P. Guillemin, P. Friess, O Vermesan, M. Hrrison, H. Vogt, K. Kalaboukas, M. Tomasella, K. Wouters, S. Gusmeroli, dan S. Haller, "Internet of Things: Strategic Research Roadmap," CERPIoT SRA version European Commission (EC) DG INFSO-D4 Unit for the European and International IoT stakeholders 15 September 2009.

[20]E Palantei, "Switched Parasitic Smart Antenna: Design and Implementation for Wireless Communication Systems," $\mathrm{PhD}$ Thesis, Griffith University, Brisbane, Australia, May 2012. 